\title{
Analisis Pengaruh Variasi Heat Input dan Bentuk Kampuh pada Penglasan SMAW Weld Joint Pelat Baja A 36 Terhadap Sifat Mekanik
}

\author{
(ITS) \\ e-mail: hermanp@oe.its.ac.id
}

Robby Nur Fridayan, Herman Pratikno, dan Hasan Ikhwani

Departemen Teknik Kelautan, Fakultas Teknologi Kelautan, Institut Teknologi Sepuluh Nopember

\begin{abstract}
Abstrak - Penelitian ini bertujuan untuk mengetahui pengaruh variasi heat input dan bentuk kampuh pada pengelasan SMAW pelat baja A36 terhadap kekuatan mekanik. Variasi heat input 25 $\mathrm{kj} / \mathrm{mm}, 34 \mathrm{kj} / \mathrm{mm}, 57 \mathrm{kj} / \mathrm{mm}$ dan variasi bentuk kampuh yaitu single $\mathrm{V}$, U, dan double $\mathrm{V}$. Ketebelan pelat baja A $3610 \mathrm{~mm}$, menggunakan elektroda $\mathrm{E} 7018$ dengan diameter $3,2 \mathrm{~mm}$. Material di uji mekanis yaitu, uji tarik dan uji kekerasan. Dengan teori semakin tinggi nilai ultimate strength nya maka akan tinggi juga nilai dari kekerasannya. Spesimen dengan heat input $25 \mathrm{kj} / \mathrm{mm}$ dengan kampuh berbentuk single $\mathrm{V}$ memiliki nilai ultimate strength dan kekerasan, masing-masing sebesar 509,15 Mpa dan $178 \mathrm{HVN}$. Spesimen dengan heat input $34 \mathrm{kj} / \mathrm{mm}$ dengan kampuh berbentuk single $\mathrm{V}$ memiliki nilai ultimate strength dan kekerasan masing-masing sebesar 479,12 Mpa dan 186,6 HVN. Spesimen dengan heat input $57 \mathrm{kj} / \mathrm{mm}$ dengan kampuh berbentuk single $\mathrm{V}$ memiliki nilai ultimate strength dan kekerasan masing-masing sebesar 494,74 Mpa dan 152,67 HVN. Spesimen dengan heat input $25 \mathrm{kj} / \mathrm{mm}$ dengan kampuh berbentuk $U$ memiliki nilai ultimate strength dan kekerasan, laju korosi masing-masing sebesar 474,2 Mpa dan 180,33 HVN. Spesimen dengan heat input $34 \mathrm{kj} / \mathrm{mm}$ dengan kampuh berbentuk $U$ memiliki nilai ultimate strength dan kekerasan masing-masing sebesar 510,18 Mpa dan 181,67 HVN. Spesimen dengan heat input $57 \mathrm{kj} / \mathrm{mm}$ dengan kampuh berbentuk $U$ memiliki nilai ultimate strength dan kekerasan masing-masing sebesar 513,33 Mpa dan 187,33 HVN. Spesimen dengan heat input $25 \mathrm{kj} / \mathrm{mm}$ dengan kampuh berbentuk double $\mathrm{V}$ memiliki nilai ultimate strength dan kekerasan masing-masing sebesar 501,89 Mpa dan 164,33 HVN. Spesimen dengan heat input 34 $\mathrm{kj} / \mathrm{mm}$ dengan kampuh berbentuk double $\mathrm{V}$ memiliki nilai ultimate strength dan kekerasan, laju korosi masing-masing sebesar 527,48 Mpa dan 192,33 HVN. Spesimen dengan heat input $57 \mathrm{kj} / \mathrm{mm}$ dengan kampuh berbentuk double $\mathrm{V}$ memiliki nilai ultimate strength dan kekerasan masing-masing sebesar 489,02 Mpa dan 149,67 HVN.
\end{abstract}

Kata Kunci-Pengelasan, Heat input, Kampuh, Ultmate Strength, Kekerasan.

\section{PENDAHULUAN}

M INYAK dan gas merupakan sumber energi yang sangat diperlukan di dunia dan semakin dibutuhkan keberadaannya. Dengan kebutuhannya yang semakin meningkat maka hal ini berbanding lurus dengan kebutuhan akan konstruksi bangunan lepas pantai guna mengoptimalkan eksplorasi dan eksploitasi minyak dan gas. Sedangkan konstruksi lepas pantai sangat berkaitan dengan pengelasan.
Las sudah lahir dari 4000 sampai 3000 S.M. Pada tahun 1920-an las sudah berperan vital terhadap pembangunan kapal laut, jembatan kereta api dan pembangunan gedung Sharon yang semua rangka bajanya dilas. Berdasarkan [1], pengelasan merupakan proses penyambungan dua logam paduan atau lebih yang dilaksanakan dalam keadaan lumer atau cair sehingga setelah membeku akan terbentuk sambungan melalui ikatan kimia yang dihasilkan dari pemakaian energi panas, sedangkan definisi dari Dutche Industrie Normen (DIN) las adalah ikatan metalurgi pada sambungan logam atau logam paduan yang dilaksanakan dalam keadaan lumer atau cair.

Terdapat jenis-jenis dalam pengelasan diantaranya adalah las tekan dingin, las listrik terak, las busur, las termit, las laser, las SMAW, las GMAW, dan lain-lain. SMAW (Shielded Metal Arc Welding) merupakan salah satu jenis pengelasan yang sering digunakan. Dalam pengelasan SMAW logam induk mengalami pencairan akibat pemanasan dari busur listrik yang timbul antara ujung elektroda dan permukaan benda kerja dan busur listrik itu sendiri dibangkitkan dari suatu mesin las. Elektoda yang dipakai berupa kawat yang dibungkus oleh pelindung berupa fluks. Elektroda ini selama pengelasan akan mengalami pencairan bersama-sama dengan logam induknya menjadi bagian kampuh las. Dengan adanya pencairan ini maka kampuh las akan terisi oleh logam cair yang berasal dari elektroda dan logam induk [2].

Pada sebelumnya telah dilakukan penelitian [3] tentang analisis variasi arus dan kampuh pada pengelasan SMAW terhadap kekuatan impact sambungan butt joint pada pelat baja A36. Dengan penelitian ini maka akan dilakukan penelitian lanjut tentang analisis pengaruh variasi heta input dan bentuk kampuh pada pengelasan SMAW terhadap kekuatan tarik dan kekerasan material pada weld joint pelat baja A36 di lingkungan laut.

\section{METODOLOGI PENELITIAN}

\section{A. Tahap Persiapan Spesimen dan Pengelasan.}

Material yang digunakan pada penelitian ini adalah pelat baja ASTM A 36 dengan ukuran panjang $300 \mathrm{~mm}$, lebar 150 $\mathrm{mm}$, dan tebal $10 \mathrm{~mm}$. Dan variasi kampuh yaitu single $\mathrm{V}, \mathrm{U}$, dan double $\mathrm{V}$. 


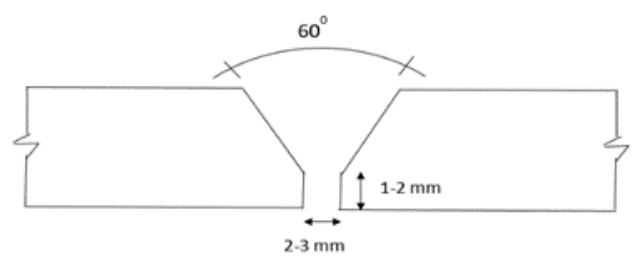

Gambar 1. Ukuran Pelat Baja A 36 Kampuh Bentuk Single V

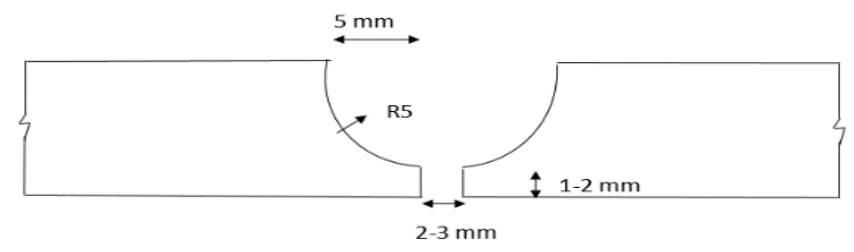

Gambar 2. Ukuran Pelat Baja A 36 Kampuh Bentuk U

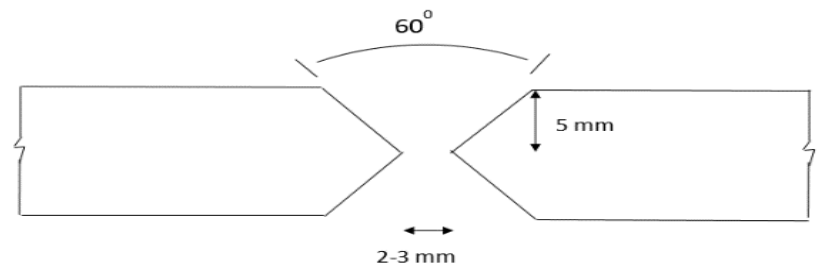

Gambar 3.Ukuran Pelat Baja A 36 Kampuh Bentuk Double V

Pengelasan menggunakan Shielded Metal Arc Welding (SMAW). Dengan variasi heat input adalah $25 \mathrm{kj} / \mathrm{mm}, 34$ $\mathrm{kj} / \mathrm{mm}, 57 \mathrm{kj} / \mathrm{mm}$. Elektroda yang digunakan adalah tipe E7018 dengan diameter 3,2 mm. Pengelasan menggunakan Shielded Metal Arc Welding (SMAW). Dengan variasi heat input adalah $25 \mathrm{kj} / \mathrm{mm}, 34 \mathrm{kj} / \mathrm{mm}, 57 \mathrm{kj} / \mathrm{mm}$. Elektroda yang digunakan adalah tipe E7018 dengan diameter 3,2 mm.

\section{B. Tahap Inspeksi}

Setelah proses pengelasan dilakukan maka pelat baja A 36 akan diuji NDT menggunakan metode Radiographic Testing yang berpedoman dengan standar. Pengujian radiografi ini dilakukan di PT. Robutech Surabaya yang beralamat di Semolowaru Selatan V No.25, Sukolilo, Kota Surabaya, Jawa Timur.

\section{Tahap Pembuatan Spesimen dan Pengujian}

Pengujian tarik berfungsi unetuk mengetahui nilai ultimate strength dan yield strength dari material tersebut. Pengujian dilakukan di Laboratorium Konstruksi dan Kekuatan Kapal Teknik Perkapalan FTK-ITS Surabaya. Terdapat dua buah spesimen pada masing-masing variasi pengelasan sehingga total dari spesimen uji tarik ialah 18 spesimen. Pembentukan spesimen uji tarik sesui dengan standar [4].

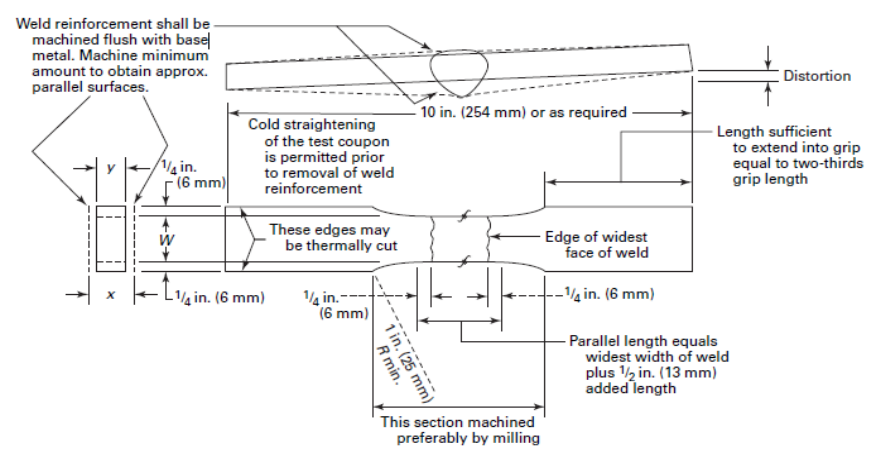

Gambar 4. Ukuran Spesimen Uji Tarik

Pengujian kekerasan (vickers hardness test) berfungsi untuk mengetahui kekerasan dari material tersebut. Pengujian dilakukan di Laboratorium Konstruksi dan Kekuatan Kapal Teknik Perkapalan FTK-ITS Surabaya. Terdapat total 9 spesimen untuk pengujian ini, tiap spesimennya dilakukan pengujian pada 3 daerah dan terdapat 3 titik pada masingmasing daerahnya. Pengujian ini berpediman pada standar [5].

\section{HASIL DAN DISKUSI}

\section{A. Hasil Pengujian Tarik}

Tabel 1. Hasil Uji Tarik

\begin{tabular}{|c|c|c|}
\hline No. Material & Yield Strength (Mpa) & Ultimate Strength (Mpa) \\
\hline 1.1 & 397,0511256 & 499,6901921 \\
\hline 1.2 & 414,8912312 & 518,614039 \\
\hline 2.1 & 359,9584273 & 475,0437273 \\
\hline 2.2 & 371,2871287 & 483,1889439 \\
\hline 3.1 & 383,3005283 & 501,398529 \\
\hline 3.2 & 351,6680254 & 488,0725928 \\
\hline 4.1 & 365,9072059 & 468,3612236 \\
\hline 4.2 & 364,3310095 & 480,030722 \\
\hline 5.1 & 373,8025823 & 507,6009996 \\
\hline 5.2 & 380,2007871 & 512,7572778 \\
\hline 6.1 & 380,0499792 & 519,0545606 \\
\hline 6.2 & 361,1283481 & 507,6142132 \\
\hline 7.1 & 387,9835938 & 509,9212948 \\
\hline 7.2 & 375,4230118 & 493,8663283 \\
\hline 8.1 & 382,8236208 & 533,2571281 \\
\hline 8.2 & 377,4862022 & 521,711965 \\
\hline 9.1 & 366,8894808 & 482,4847967 \\
\hline 9.2 & 358,2267775 & 495,5470421 \\
\hline
\end{tabular}

Spesimen 1.1 dengan heat input sebesar $25 \mathrm{kj} / \mathrm{mm}$ dan kampuh berbentuk single $\mathrm{V}$, spesimen 1.2 dengan heat input sebesar $25 \mathrm{kj} / \mathrm{mm}$ dan kampuh berbentuk single V. Spesimen 2.1 dengan heat input sebesar $34 \mathrm{kj} / \mathrm{mm}$ dan kampuh berbentuk single $\mathrm{V}$, spesimen 2.2 dengan heat input sebesar $34 \mathrm{kj} / \mathrm{mm}$ dan kampuh berbentuk single V. Spesimen 3.1 dengan heat input sebesar $57 \mathrm{kj} / \mathrm{mm}$ dan kampuh berbentuk single $\mathrm{V}$, spesimen 3.2 dengan heat input sebesar $57 \mathrm{kj} / \mathrm{mm}$ dan kampuh berbentuk single $\mathrm{V}$.

Spesimen 4.1 dengan heat input sebesar $25 \mathrm{kj} / \mathrm{mm}$ dan kampuh berbentuk $\mathrm{U}$, spesimen 4.2 dengan heat input sebesar $25 \mathrm{kj} / \mathrm{mm}$ dan kampuh berbentuk U. Spesimen 5.1 dengan heat input sebesar $34 \mathrm{kj} / \mathrm{mm}$ dan kampuh berbentuk U, 
Spesimen 5.2 dengan heat input sebesar $34 \mathrm{kj} / \mathrm{mm}$ dan kampuh berbentuk U. Spesimen 6.1 dengan heat input sebesar $57 \mathrm{kj} / \mathrm{mm}$ dan kampuh berbentuk U, spesimen 6.2 dengan heat input sebesar $57 \mathrm{kj} / \mathrm{mm}$ dan kampuh berbentuk U.

Spesimen 7.1 dengan heat input sebesar $25 \mathrm{kj} / \mathrm{mm}$ dan kampuh berbentuk double $\mathrm{V}$, spesimen 7.2 dengan heat input sebesar $25 \mathrm{kj} / \mathrm{mm}$ dan kampuh berbentuk double V. Spesimen 8.1 dengan heat input sebesar $34 \mathrm{kj} / \mathrm{mm}$ dan kampuh berbentuk double $\mathrm{V}$, spesimen 8.2 dengan heat input sebesar $34 \mathrm{kj} / \mathrm{mm}$ dan kampuh berbentuk double V. Spesimen 9.1 dengan heat input sebesar $57 \mathrm{kj} / \mathrm{mm}$ dan kampuh berbentuk double $\mathrm{V}$, spesimen 9.2 dengan heat input sebesar $57 \mathrm{kj} / \mathrm{mm}$ dan kampuh berbentuk double V. Spesimen 8 merupakan sepsimen yang memiliki ultimate strength yang paling tinggi yaitu sebesar 527,48 Mpa.

Tabel 2

Summary Kekuatan Tarik Setiap Spesimen

\begin{tabular}{|c|c|c|c|}
\hline Spesimen & Ultimate Strength (Mpa) & Kontingensi (100\%) & Breaking \\
\hline Baja ASTM A 36 & 424,50 & 100,00 & Base Metal \\
\hline 1 & 509,15 & 119,94 & Base Metal \\
\hline 2 & 479,12 & 112,87 & Base Metal \\
\hline 3 & 494,74 & 116,55 & Base Metal \\
\hline 4 & 474,20 & 111,71 & Base Metal \\
\hline 5 & 510,18 & 120,18 & Base Metal \\
\hline 6 & 513,33 & 120,93 & Base Metal \\
\hline 7 & 501,89 & 118,23 & Base Metal \\
\hline 8 & 527,48 & 124,26 & Base Metal \\
\hline 9 & 489,02 & 115,20 & Base Metal \\
\hline
\end{tabular}

Setelah diambil nilai rata-rata pada setiap sepesimen, maka dihitung nilai kontingensi nya agar dapat diketahui apakah pengujian ini sesuai dengan standar [1]. Dari tabel di atas dapat dilihat bahwa kontingensi dari setiap spesimen lebih dari $5 \%$, dan putus pada daerah logam induk (logam dasar). Maka, dari data tabel 3.2 dapat dinyatakan bahwa pengujian dari semua spesimen dinyatakan diterima sesuai dengan standar ASME IX 2002.

\section{B. Hasil uji Kekerasan}

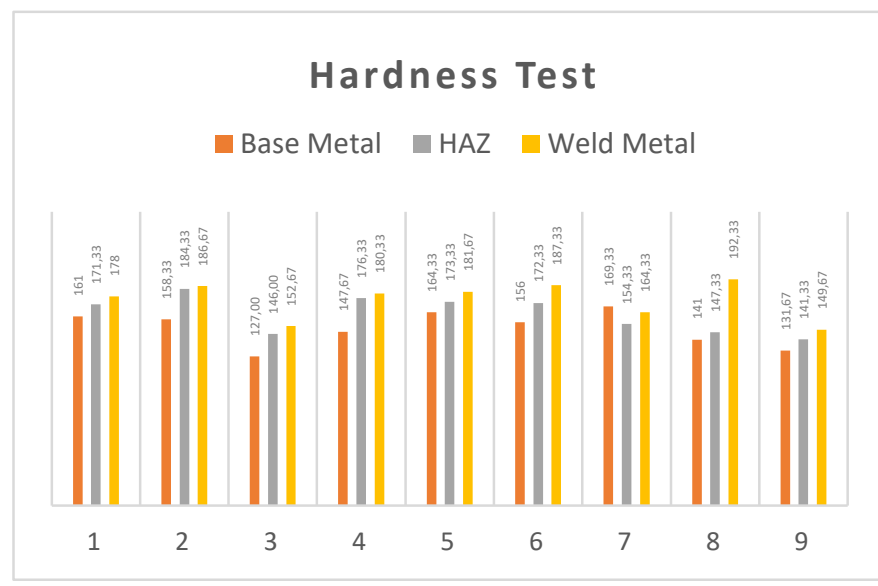

Gambar 5. Grafil Hasil Uji Kekerasan

Spesimen 1 dengan heat input sebesar $25 \mathrm{kj} / \mathrm{mm}$ dan kampuh berbentuk single $\mathrm{V}$, spesimen 2 dengan heat input sebesar $34 \mathrm{kj} / \mathrm{mm}$ dan kampuh berbentuk single $\mathrm{V}$, spesimen 3 dengan heat input sebesar $57 \mathrm{kj} / \mathrm{mm}$ dan kampuh berbentuk single $\mathrm{V}$, spesimen 4 dengan heat input sebesar $25 \mathrm{kj} / \mathrm{mm}$ dan kampuh berbentuk U, spesimen 5 dengan heat input sebesar 34 $\mathrm{kj} / \mathrm{mm}$ dan kampuh berbentuk U Spesimen 6 dengan heat input sebesar $57 \mathrm{kj} / \mathrm{mm}$ dan kampuh berbentuk U, spesimen 7 dengan heat input sebesar $25 \mathrm{kj} / \mathrm{mm}$ dan kampuh berbentuk double $\mathrm{V}$, spesimen 8 dengan heat input sebesar $34 \mathrm{kj} / \mathrm{mm}$ dan kampuh berbentuk double $\mathrm{V}$.

Pada pengujian kekerasan dilakukan pengujian pada 3 daerah pada setiap spesimen, dan dilakukan pengujian 3 titik pada setiap daerah. Dari grafik diatas dapat disimpulkan bahwa spesimen 8 memiliki nilai kekerasan tertinggi yaitu 192,33 HVN pada daerah logam lasnya, dan hal ini berbanding lurus dengan hasil uji tarik dan pengamatan struktur mikroMetode least-square inversion sering digunakan untuk membuat model inversi dikarenakan metode ini dapat menghasilkan model inversi yang baik ketika data observasi yang dimiliki lebih banyak dibanding data yang akan dihitung.

\section{KESIMPULAN}

\section{A. Simpulan}

Pada penelitian studi tentang pengelasan SMAW terhadap material baja ASTM A 36 dengan variasi heat input dan bentuk kampuh dengan menitik beratkan sifat mekanis dan ketahanan korosi di lingkungan laut dapat dihasilkan beberapa kesimpulan sebagai berikut:

- Pada uji tarik dilakukan pengujian 2 spesimen di tiap variasi nya. Heat input $34 \mathrm{kj} / \mathrm{mm}$ dengan kampuh berbentuk double $\mathrm{V}$ menjadi variasi yang memiliki ultimate strenght tertinggi yaitu 527,48 Mpa. Sedangkan heat input $25 \mathrm{kj} / \mathrm{mm}$ dengan kampuh berbentuk $U$ menjadi variasi yang memiliki ultimate strenght terendah yaitu 474,2 Mpa. Heat input $25 \mathrm{kj} / \mathrm{mm}$ dengan kampuh berbentuk single $\mathrm{V}$ menjadi variasi yang memiliki yield strenght tertinggi yaitu 405,97 Mpa. Sedangkan heat input $57 \mathrm{kj} / \mathrm{mm}$ dengan kampuh berbentuk double $\mathrm{V}$ menjadi variasi yang memiliki yield strenght terendah yaitu 362,56 Mpa.

- Uji Vickers Hardness dilakukan penembakan 3 titik pada masing-masing daerah, daerah tersebut meliputi logam induk (base metal), HAZ, logam las (weld metal). Kekerasan pada logam induk memiliki nilai yang tidak jauh berbeda pada tiap variasi nya dengan rata-rata 150,7 HVN. Heat input $34 \mathrm{kj} / \mathrm{mm}$ dengan kampuh berbentuk double $\mathrm{V}$ menjadi spesimen yang terkeras dengan nilai kekerasan pada logam las sebesar 192,33 HVN, hal ini sebanding lurus dengan nilai ultimate strenght yang tinggi pula. Sedangkan heat input $57 \mathrm{kj} / \mathrm{mm}$ dengan kampuh berbentuk double $\mathrm{V}$ menjadi variasi yang memiliki nilai kekerasan pada daerah logam las dan HAZ terendah yaitu 149,67 HVN dan 141,33 HVN.

\section{B. Saran}

Terdapat beberapa hal yang dapat dijadikan saran yang sifatnya membangun penelitian selanjutnya adalah sebagai berikut:

- Proses pre heat dan post heat pada pengelasan baja merupakan salah satu hal yang penting dalam proses 
pengelasan, namun dalam penelitian ini tidak dilakukan sehingga perlu dilakukan penelitian lebih lanju tentang variasi post heat dan pre heat yang optimal.

- Pada penelitian selanjutnya dapat ditambahkan variasi dari sudut kampuh double $\mathrm{V}$ guna mengetahui pengaruh kekuatan mekanik dan laju korosinya.

- Analisis pengujian impact dapat ditambahkan pada penelitian selanjutnya.

\section{DAFTAR PUSTAKA}

D. Suprijanto, "Pengaruh Bentuk Kampuh Terhadap Kekuatan Bending Las Sudut SMAW Posisi Mendatar pada Baja Karbon
Rendah," in SEMINAR NASIONAL ke8-Tahun 2013: Rekayasa Teknologi Industri dan Informasi, 2013.

[2] G. Katsas, S., Nikolaou, J., Papadimitriou, "Microstructural changes accompanying repair weling in $5 \times x x$ alumunium alloys and their effect on the mechanical properties," Mater. Des., vol. 27, pp. 968$975,2005$.

[3] S. . Khotasa, Analisis Pengaruh Variasi Arus dan Bentu Kampuh Pada Pengelasan SMAW Terhadap Kekuatan Impact Sambungan Butt Joint pada Pelat Baja A36. Surabaya: Institut Teknologi Sepuluh Nopember, 2016.

[4] A. E92, Standard Test Method for Vickers Hardness of Metallic Materials. Washington D.C.: ASTM Publishing, 2004.

[5] A. section IX, Qualification Standard For Welding, Brazing, And Fusing Procedures; Welders, Brazers, And Welding, Brazing, And Fusing Operators. 2002. 